\title{
Neurochemical Characterization of Excitotoxin Lesions in the Cerebral Cortex
}

\author{
M. Flint Beal,, Kenton J. Swartz,, ${ }^{1,2}$ Stephen F. Finn, ${ }^{1}$ Michael F. Mazurek, ${ }^{3}$ and Neil W. Kowall ${ }^{1}$ \\ 'Neurochemistry Laboratory, Neurology Service, Massachusetts General Hospital and Harvard Medical School, Boston, \\ Massachusetts 02114, 2Program in Neuroscience, Harvard Medical School, Boston, Massachusetts 02114, and ${ }^{3}$ Neurology \\ Division, Department of Medicine, McMaster University Medical Center, Hamilton, Ontario, Canada L8N $3 Z 5$
}

Neuronal degeneration that occurs in both ischemia and degenerative neurologic illnesses may involve excitotoxic mechanisms. In the present study, we examined whether cortical lesions with agonists acting at subtypes of glutamate receptors result in selective patterns of neuronal death. Injections of quinolinic acid, NMDA, homocysteic acid, kainic acid (KA), and $\alpha$-amino-3-hydroxy-5-methylisoxazole-4-proprionic acid (AMPA) were made at 2 sites in the dorsolateral frontoparietal cortex in rats. After 1 week, the cerebral cortex was either dissected for neurochemical studies, or animals were perfused for histologic evaluation. Concentrations of somatostatin (SS), neuropeptide $Y$ (NPY), substance P (SP), cholecystokinin (CCK), and vasoactive intestinal polypeptide (VIP) were measured by radioimmunoassay, while amino acids and catecholamines were measured by high-performance liquid chromatography (HPLC) with electrochemical detection. NMDA agonists (quinolinic acid, homocysteic acid, and NMDA itself) resulted in dose-dependent reductions in glutamate and GABA, while SS, NPY, SP, CCK, and VIP were either unchanged or significantly increased in concentration. KA and AMPA at doses that resulted in comparable GABA depletions caused significant reductions in SS concentrations. Markers of cortical afferents were spared. All excitotoxins resulted in dose-dependent marked increases in uric acid concentrations. Histologic examination verified that lesions with NMDA agonists produced relative sparing of NADPH-diaphorase, SS, VIP, and CCK neurons. These results show that NMDA excitotoxin lesions result in a pattern of selective neuronal damage in the cerebral cortex that is similar to that which occurs in both ischemia and Huntington's disease.

An accumulating body of evidence suggests the involvement of acidic amino acid receptors in a variety of neuropathologic states, including ischemia and hypoglycemia (Simon et al., 1984; Wieloch, 1985; Choi, 1988). Excitatory amino acids may also play a role in Alzheimer's disease (AD; Greenamyre et al., 1988). The possibility that an excitotoxic process may occur in Huntington's disease (HD) was initially proposed on the basis of

\footnotetext{
Received May 16, 1990; revised Aug. 16, 1990; accepted Sept. 4, 1990.

The secretarial assistance of Sharon Melanson is gratefully acknowledged. This work was supported by NINDS 16367 (Huntington's Disease Center Without Walls) and NINDS Stroke Grant NS10828-14A1.

Correspondence should be addressed to Dr. M. Flint Beal, Neurology Research 4, Massachusetts General IIospital, Boston, MA 02114.

Copyright (C) 1991 Society for Neuroscience $0270-6474 / 91 / 010147-12 \$ 03.00 / 0$
}

both pathologic and neurochemical similarities with excitotoxin lesions (Coyle and Schwarcz, 1976; McGeer and McGeer, 1976; Schwarcz et al., 1984). We found that striatal excitotoxin lesions with NMDA agonists provide a more accurate model of HD than those with other excitotoxins, because they result in relative sparing of somatostatin (SS) and neuropeptide Y (NPY) as compared with GABA and substance $P$ (SP), similar to findings in HD (Beal et al., 1986a, 1989). The possibility of an NMDA excitotoxin mechanism in $\mathrm{HD}$ has been strengthened by the observation that NMDA receptors are preferentially depleted in the HD striatum (Young et al., 1989).

We recently found that both ischemia and HD result in selective patterns of neuronal vulnerability in the cerebral cortex (Beal et al., 1988b; Cudkowicz and Kowall, 1990; Uemura et al., 1990). Differential vulnerability of cortical neurons in AD is also suggested by both neurochemical and histologic studies (Beal et al., 1987; Kowall and Beal, 1988). A suitable animal model of these illnesses should replicate the same pattern of neuronal vulnerability. In the striatum in vivo and in cortical and striatal cell cultures in vitro, excitotoxin lesions with NMDA and non-NMDA excitatory amino acid agonists show differing patterns of neuronal susceptibility (Koh and Choi, 1988a,b; Beal et al., 1989). In the present study, we examined the effects of lesions in the cerebral cortex with NMDA, kainic acid (KA), and quisqualate agonists, to determine whether lesions with particular agonists could mimic the patterns of neuronal degeneration seen in either ischemia or neurodegenerative illnesses.

\section{Materials and Methods}

Kainic acid, quinolinic acid, homocysteic acid, and $N$-methyl-D-aspartate were obtained from Sigma (St. Louis, MO), while $\alpha$-amino-3-hydroxy-5-methylisoxazolc-4-proprionic acid (AMPA) was obtained from Research Biochemicals (Wayland, MA). Male Sprague-Dawley rats (Charles River) weighing 150-175 gm were anesthetized with pentobarbital ( $50 \mathrm{mg} / \mathrm{kg}$, i.p.). Compounds were dissolved in $1 \mu \mathrm{l}$ phosphatebuffered saline $(\mathrm{pH}, 7.4)$ and were injected into the left dorsolateral frontoparietal cortex at 2 sites: $1.7 \mathrm{~mm}$ anterior to the bregma, $2.0 \mathrm{~mm}$ lateral, $2.6 \mathrm{~mm}$ ventral to the skull surface; and $1.8 \mathrm{~mm}$ posterior to the bregma, $3.0 \mathrm{~mm}$ lateral, $2.3 \mathrm{~mm}$ ventral to the skull. The incisor bar (Kopf stereotaxic) was set at $-3.3 \mathrm{~mm}$. Injections were made with a 10- $\mathrm{ll}$ Hamilton syringe fitted with a 30-gauge blunt-tipped needle. All injections were made over $1 \mathrm{~min}$, and the needle was left in place for a further 2 min before being slowly withdrawn.

Ten animals were lesioned at each dose of excitotoxin. All animals survived for 1 week and were killed by decapitation, their brains were promptly rcmoved, and the dorsolateral cerebral cortex was dissected from a 3-mm-thick slice, using a Plexiglas brain template (Zivic-Miller). The left and right cerebral cortex were placed in $1 \mathrm{ml}$ chilled $0.1 \mathrm{~N} \mathrm{HCl}$. Samples were sonicated, frozen, and thawed twice, and 2 aliquots were taken for analysis of catecholamines and amino acids. The remaining 
Table 1. Neurochemical markers in control cerebral cortex

\begin{tabular}{lll} 
& Left & Right \\
\hline Glutamate & $97.0 \pm 3.4$ & $100.3 \pm 5.1$ \\
Aspartate & $29.3 \pm 1.8$ & $29.9 \pm 2.6$ \\
GABA & $21.5 \pm 1.2$ & $19.1 \pm 0.7$ \\
Somatostatin (SS) & $0.89 \pm 0.06$ & $0.91 \pm 0.08$ \\
Neuropeptide Y (NPY) & $2.03 \pm 0.08$ & $2.11 \pm 0.08$ \\
Substance P (SP) & $16.2 \pm 0.7$ & $17.8 \pm 1.5$ \\
Vasoactive intestinal & & \\
$\quad$ polypeptide (VIP) & $0.68 \pm 0.04$ & $0.62 \pm 0.02$ \\
Cholecystokinin (CCK) & $0.60 \pm 0.62$ & $0.60 \pm 0.03$ \\
\hline
\end{tabular}

$\overline{n=10}$; amino acids are nmol/mg protein; neuropeptides are $\mathrm{pmol} / \mathrm{mg}$ protein, except $\mathrm{SP}$, which is $\mathrm{fmol} / \mathrm{mg}$ protein.

sample was boiled and centrifuged. Aliquots of supernatant were lyophilized for radioimmunoassays. Protein determinations were made on the pellet using a fluorometric assay (Bohlen et al., 1973). Radioimmunoassays for somatostatinlike immunoreactivity, neuropeptide Y-like immunoreactivity, substance P-like immunoreactivity, vasoactive intestinal polypeptide-like immunoreactivity, and cholecystokinin-like immunoreactivity were carried out as previously described (Arnold et al., 1982; Abe et al., 1985; Beal et al., 1986b; Beal and Mazurek, 1987; Mazurek et al., 1989a). Amino acids were measured by high-performance liquid chromatography (HPLC) with electrochemical detection (Ellison et al., 1987). Catecholamines and related compounds were assayed by a novel HPLC technique with 16-channel electrochemical detection (Matson et al., 1987).

A total of 12 animals was used for histochemical studies. Four groups of 3 animals were lesioned with quinolinic acid ( $240 \mathrm{nmol})$, NMDA $(240 \mathrm{nmol}), \mathrm{KA}(10 \mathrm{nmol})$, or AMPA $(15 \mathrm{nmol})$. After 1 week of survival, animals were deeply anesthetized with pentobarbital and perfused with $0.25 \%$ sodium nitrite in $0.9 \%$ saline, followed by fixation with $4 \%$ paraformaldehyde and $0.02 \%$ glutaraldehyde in $0.1 \mathrm{M}$ phosphate buffer (pH, 7.3). Brains were removed, washed in phosphate buffer, and cut at $50 \mu \mathrm{m}$ on a vibratome. Sets of sections were placed in normal goat serum in phosphate-buffered saline (PBS) for $1 \mathrm{hr}$, followed by incubation overnight at room temperature in antisera to SS $(1: 1000 ;$ ICN), VIP (1:1000; Incstar), CCK (1:1000; Incstar), and SMI-32 (a monoclonal antibody that recognizes a phosphatase-insensitive epitope on the medium and heavy chain of the neurofilament polypeptide; 1:5000; Sternberger-Meyer). Somatostatin, VIP, and CCK immunoreactivity are located in cortical local circuit neurons, whereas SMI-32 is found in a subset of cortical pyramidal projection neurons that are sensitive to degeneration in HD (Cudkowicz and Kowall, 1990). After washes in PBS and incubation in the appropriate peroxidase-conjugated secondary antibodies, immunoreactivity was disclosed using diaminobenzidine as the chromagen (Kowall and Beal, 1988). Adjacent sections were stained with cresyl violet. Cortical sections from animals lesioned with NMDA or KA were stained for NADPH-diaphorase with a cresyl violet counterstain as previously described (Beal et al., 1989).

The injections resulted in several-millimeter-wide regions of dense gliosis surrounding the needle tract in which there were few remaining neurons. Examination of coronal sections at a level where the lesion was clearly visible showed a small transition zone of partial neuronal depletion extending from the intensely lesioned areas to normal-appearing cortex. Neuronal counts of immunoreactive or NADPH-diaphorase neurons were made on coronal sections by 2 independent observers through the depth of the cortex across a $1.5-\mathrm{mm}$ traverse immediately around the injection site and 2 flanking $1.5-\mathrm{mm}$ regions of adjacent cortex. Neuronal counts were also manually performed on cresyl violet-stained sections and NADPH-diaphorase-cresyl violetstained sections in a series of random $320 \times$ fields within the same regions.

The neurochemical measurements were compared to the unlesioned (control) side and expressed as the percentage of control. The unlesioned control sides were compared with saline-injected contralateral unlesioned control sides. There were no significant neurochemical differences from the saline controls on the unlesioned side, except for NPY, as discussed below. The results are expressed as the mean \pm standard error of the mean. Comparisons were made using unpaired Student's $t$ test (2-tailed) or 1-way analysis of variance (ANOVA).

\section{Results}

The levels of the various neurotransmitters examined in the saline-injected control cerebral cortex are shown in Table 1. There were no significant differences in neurochemical markers between the unlesioned side in the saline controls and that in the excitotoxin-treated animals, except for NPY. NPY concentrations were significantly increased, approximately $40 \%$ from $2.11 \pm 0.08 \mathrm{pmol} / \mathrm{mg}$ protein to a mean of $2.95 \pm 0.13$, in the unlesioned side of the excitotoxin-treated animals. Bilateral increases in cortical NPY concentrations have also been observed with electroconvulsive shocks (Wahlestedt et al., 1990) and may have resulted from seizures in our animals. The increases on the unlesioned side were uniform in all groups with no significant differences among the groups. Increases of NPY on the lesioned side of the excitotoxin-treated animals showed further increases over the unlesioned side. Concentrations of NPY were therefore compared with those on the unlesioned side.

The effects of increasing doses of NMDA agonists on neurochemical markers are shown in Figures 1-3. All 3 NMDA agonists (NMDA, quinolinic acid, and L-homocysteic acid) produced a similar pattern of neurochemical changes. There were mild dose-dependent significant reductions in glutamate, while aspartate showed no significant changes. Reductions in GABA were also dose dependent and reached a maximum of $30-40 \%$ at the highest doses examined. In contrast, none of the neuropeptides showed significant depletions. NMDA resulted in significant increases of NPY, SP, and CCK. Quinolinic acid resulted in significant increases of SS and NPY, while homocysteic acid resulted in significant increases in SS, NPY, SP, and CCK. VIP concentrations showed no significant changes with any of the NMDA agonists. The increases in SS and NPY were greatest at the lowest doses of the excitotoxins, and decreased with increasing doses. This finding is consistent with relative but not absolute sparing of these neurons, which do show some vulnerability at high dose levels. In contrast, both SP and CCK showed larger increases with larger doses of the excitotoxins. Both AMPA and KA resulted in dose-dependent significant decreases in GABA concentrations (Figs. 4, 5). The highest doses examined resulted in GABA depletions comparable to those induced by NMDA agonists. In contrast to the NMDA agonists, however, both these compounds resulted in significant reductions in SS concentrations. The highest dose of KA (20 nmol) also resulted in a significant depletion of SP. NPY, VIP, and CCK showed no significant changes with KA. NPY and SP were unchanged with AMPA lesions. Unfortunately, there was insufficient sample to measure VIP and CCK with the AMPA lesions.

The results of measurements of catecholamines and related compounds are shown in Tables $2-4$. The lesions were axon sparing because there were no significant changes in concentrations of norepinephrine, dopamine, or serotonin. There was, however, evidence of increased dopamine and serotonin turnover as evidenced by dose-dependent significant increases in concentrations of 3,4-dihydroxyphenylacetic acid (DOPAC), homovanillic acid, and 5-hydroxyindoleacetic acid. Both tryptophan and tyrosine also were increased within the lesioned areas, particularly at the higher doses of the excitotoxins. The most striking neurochemical changes were dose-dependent significant increases in uric acid concentrations, with much smaller 


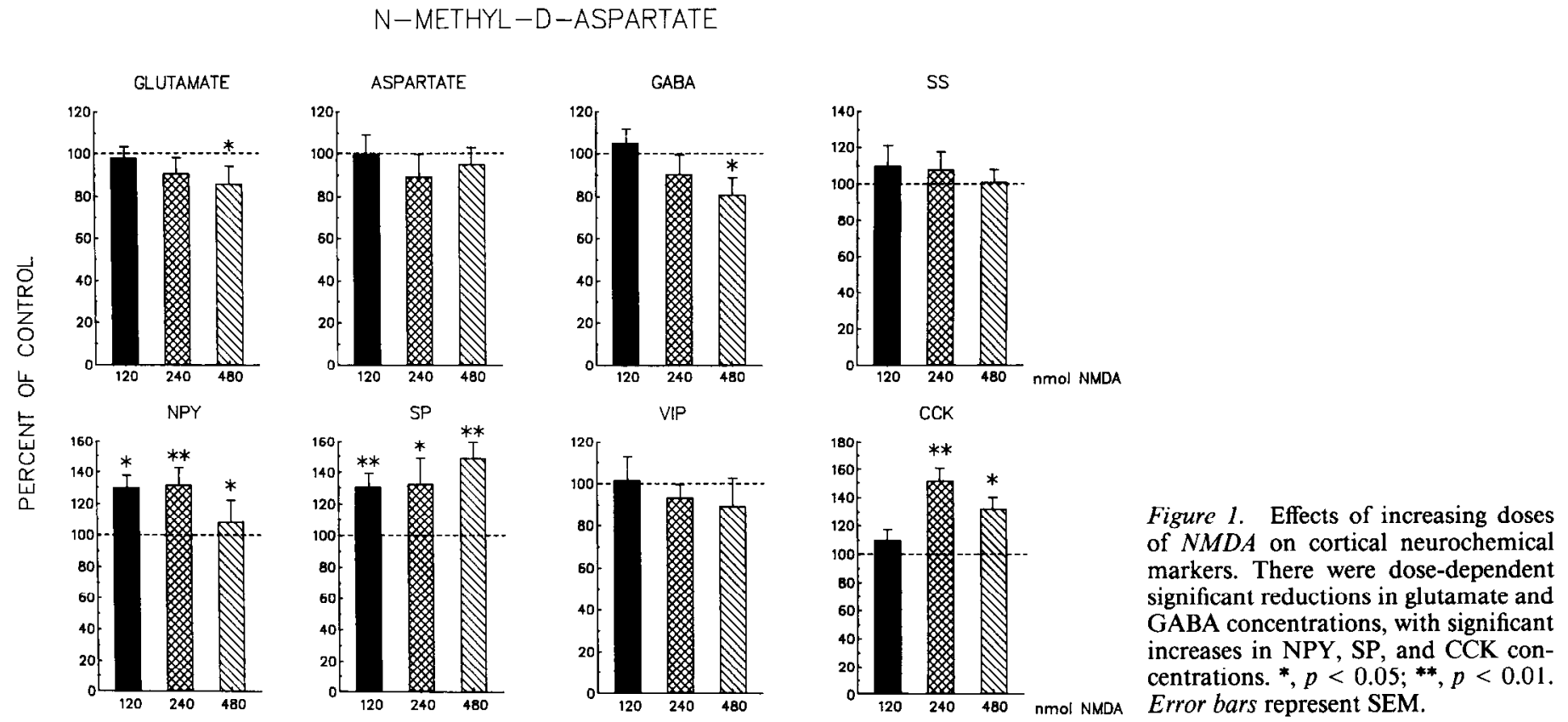

increases in xanthine concentrations. Both KA and AMPA showed similar sparing of norepinephrine, dopamine, and serotonin (data not shown). They also resulted in dose-dependent significant increases in uric acid concentrations on the lesioned side. With AMPA at the lowest dose $(7.5 \mathrm{nmol})$, uric acid increased from $18.7 \pm 1.8$ to $31.6 \pm 3.6 \mathrm{ng} / \mathrm{mg}$ protein. At 30 nmol AMPA, uric acid increased from $19.2 \pm 1.2$ to $61.4 \pm$ $6.6 \mathrm{ng} / \mathrm{mg}$ protein. With KA $(10 \mathrm{nmol})$, uric acid was significantly increased from $21.0 \pm 1.9$ to $31.0 \pm 4.6 \mathrm{ng} / \mathrm{mg}$ protein, and with $20 \mathrm{nmol} \mathrm{KA}$, from $23.0 \pm 1.2$ to $97.5 \pm 22.7 \mathrm{ng} / \mathrm{mg}$ protein.

Histochemical examination confirmed relative sparing of neuropeptide neurons after NMDA excitotoxin lesions in the

cerebral cortex. Sparing of NADPH-diaphorase, SS, VIP, and CCK neurons was seen with both NMDA and quinolinic acid. This sparing was much more striking than the sparing of NADPH-diaphorase neurons we previously observed in the transition zone of striatal lesions with NMDA agonists (Beal et al., 1989). There was some depletion of neuropeptide neurons, but it was not significant. With NMDA lesions, the mean numbers of neurons in a $1.5-\mathrm{mm}$ traverse of the unlesioned adjacent tissue as compared with those in the lesioned areas were SS, $62.4 \pm 29.3$ versus $52.3 \pm 25.4$; CCK, $10.7 \pm 0.7$ versus 7.7 \pm 0.9 ; and VIP, $46.7 \pm 9.5$ versus $38.3 \pm 11.2$. The normal pattern of SMI-32-immunoreactive pyramidal neurons in layers III and V was interrupted surrounding the injection site, while

\section{QUINOLINIC ACID}

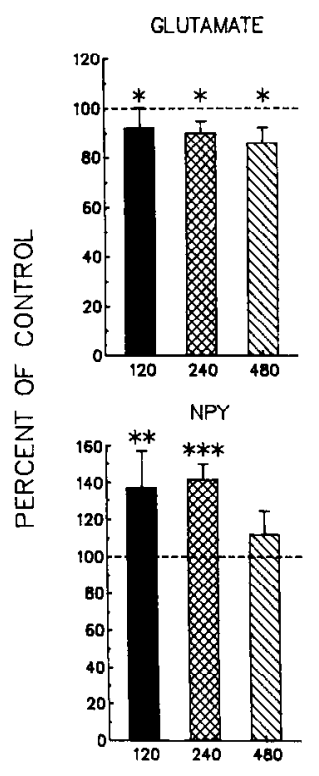

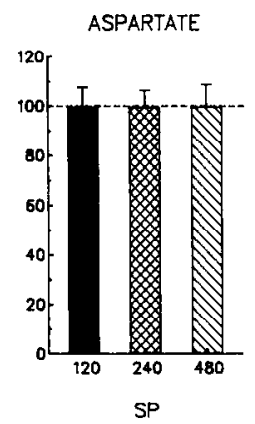
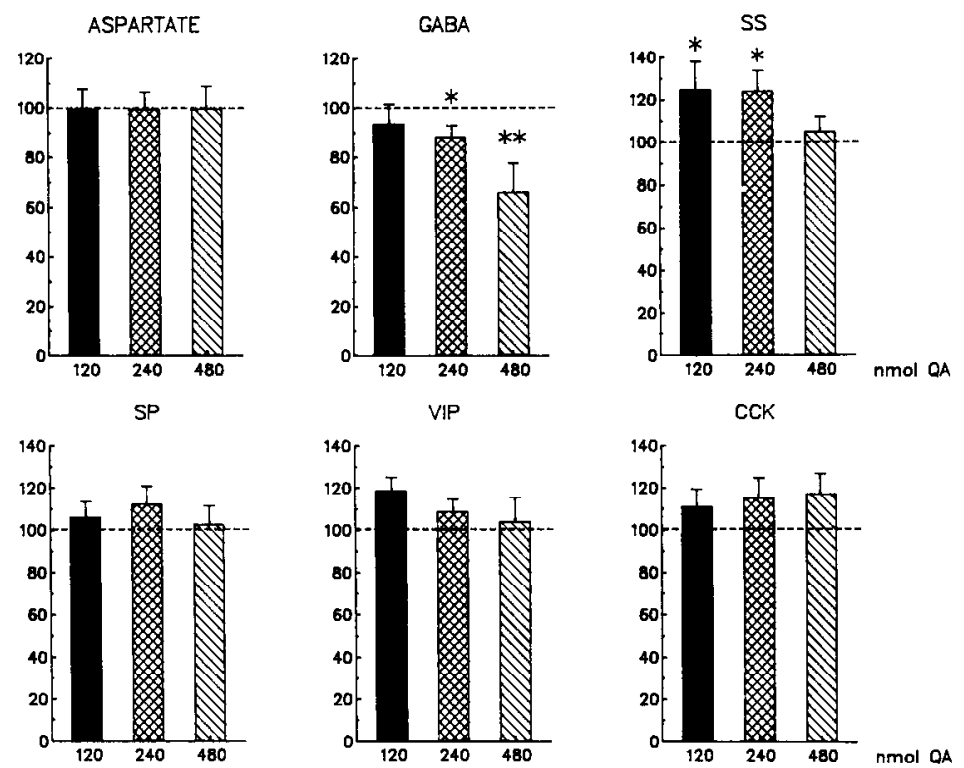

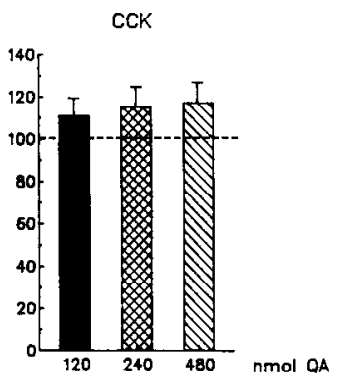

Figure 2. Effects of increasing doses of quinolinic acid $(Q A)$ on cortical neurochemical markers. There were dosedependent significant reductions in glutamate and GABA concentrations, with significant increases in SS and NPY concentrations. ${ }^{*}, p<0.05 ; * *, p<$ $0.01 ; * * *, p<0.001$. Error bars represent SEM. 
Figure 3. Effects of increasing doses of homocysteic acid (IICA) on cortical neurochemical markers. There were dose-dependent significant reductions in glutamate and GABA concentrations, with significant increases in SS, NPY, SP, and CCK concentrations. *, $p<0.05 ;{ }^{* *}, p<0.01 ;{ }^{* * *}, p<0.001$. Error bars represent SEM.
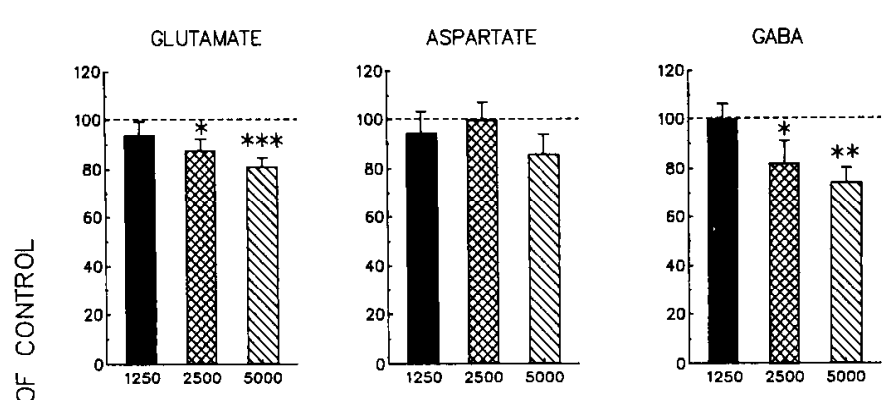

$\mathrm{SP}$
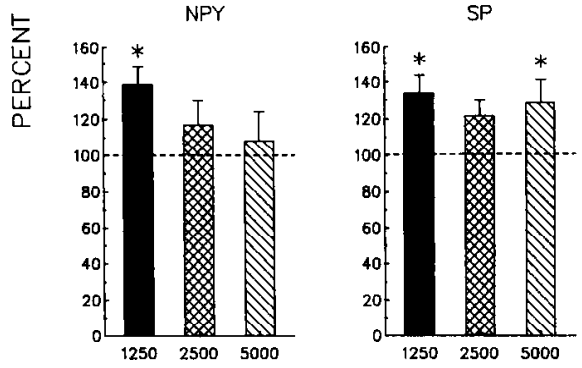

VIP

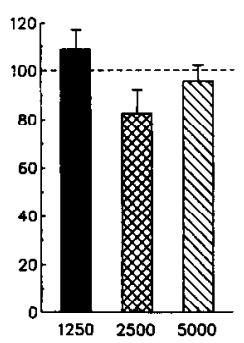

SS

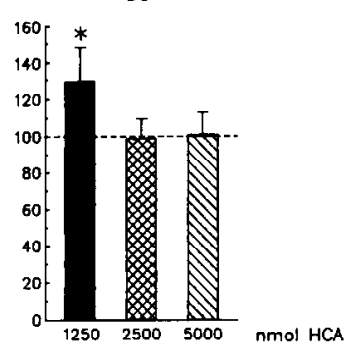

CCK

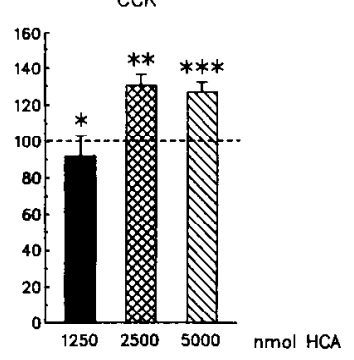

SS, CCK, and VIP neurons persisted adjacent to the necrotic injection site (Fig. 6A-D). In NADPH-diaphorase-cresyl violetstained sections, NADPH-diaphorase counts were unchanged $(10.3 \pm 1.5$ vs. $10.3 \pm 1.6)$, while there was a significant $(p<$ $0.01)$ reduction in the number of Nissl-stained neurons counted (from $880 \pm 48$ to $552 \pm 80$ neurons per mm $^{2}$; Figs. $7 A, B ; 8$ ). With quinolinic acid lesions, the mean numbers of neurons in the unlesioned tissue as compared with those in the lesioned area were SS, $37.3 \pm 5.2$ versus $29 \pm 2.4$; CCK, $10.7 \pm 0.7$ versus $10.3 \pm 3.0$; and VIP, $22.6 \pm 2.2$ versus $18.3 \pm 4.1$. In contrast, KA and AMPA resulted in significant $(p<0.01)$ depletions of SS neurons from $35.3 \pm 2.8$ to $12.7 \pm 3.5$ and from $33.7 \pm 4.3$ to $10.2 \pm 5.0$ neurons, respectively. KA lesions also resulted in a significant $(p<0.001)$ reduction of NADPH-diaphorase neurons from $10.6 \pm 0.5$ to $2.1 \pm 0.4$ neurons per 1.5 $\mathrm{mm}$ traverse, while cresyl violet-stained neuron counts fell from $960 \pm 86$ to $560 \pm 48$ per $\mathrm{mm}^{2}(p=0.005$; Fig. $7 C, D)$. It was our qualitative impression that VIP and CCK neurons were also more depleted by KA and AMPA, but there were insufficient numbers of neurons to quantitate this. SS and NADPH-diaphorase neurons were depleted approximately $20 \%$ by the NMDA agonists, but by approximately $70 \%$ by the non-NMDA agonists with comparably sized lesions.

\section{Discussion}

The neuroexcitatory and neurotoxic effects of excitatory amino acids are mediated by several types of postsynaptic receptors, commonly designated by the preferred agonists NMDA, kainate, and quisqualate (Fagg et al., 1986). More recently, it has been shown that quisqualate activates 2 types of receptors. One receptor opens a membrane ionophore and is selectively activated by AMPA, while the second receptor acts via $\mathrm{G}$-proteins to activate phospholipase $\mathrm{C}$ and is referred to as the "metabotropic" quisqualate receptor. Both NMDA and non-NMDA

Table 2. Neurochemical measurements in NMDA-lesioned cerebral cortex (ng/mg protein)

\begin{tabular}{|c|c|c|c|c|c|c|}
\hline & \multicolumn{2}{|c|}{ NMDA, $120 \mathrm{nmol}$} & \multicolumn{2}{|c|}{ NMDA, $240 \mathrm{nmol}$} & \multicolumn{2}{|c|}{ NMDA, $480 \mathrm{nmol}$} \\
\hline & Left & Right & Left & Right & Left & Right \\
\hline Norepinephrine & $1.21 \pm 1.31$ & $1.31 \pm 0.11$ & $1.39 \pm 0.14$ & $1.69 \pm 0.32$ & $1.50 \pm 0.12$ & $1.67 \pm 0.08$ \\
\hline Dopamine & $2.24 \pm 0.16$ & $2.38 \pm 0.09$ & $2.09 \pm 0.17$ & $2.67 \pm 0.31$ & $2.58 \pm 0.41$ & $3.23 \pm 0.71$ \\
\hline 3,4-Dihydroxyphenylacetic acid & $1.33 \pm 0.18$ & $0.97 \pm 0.19$ & $1.31 \pm 0.50$ & $1.17 \pm 0.67$ & $2.30 \pm 0.64$ & $1.27 \pm 0.54$ \\
\hline Homovanillic acid & $0.95 \pm 0.13^{*}$ & $0.64 \pm 0.05$ & $1.69+0.32^{*}$ & $0.78 \pm 0.26$ & $1.89 \pm 0.61^{*}$ & $0.90 \pm 0.14$ \\
\hline Serotonin & $0.46 \pm 0.04$ & $0.50 \pm 0.04$ & $0.41 \pm 0.03$ & $0.39 \pm 0.04$ & $0.43 \pm 0.08$ & $0.35 \pm 0.02$ \\
\hline 5-Hydroxyindoleacetic acid & $0.62 \pm 0.04$ & $0.57 \pm 0.03$ & $0.79 \pm 0.10^{*}$ & $0.54 \pm 0.04$ & $0.84 \pm 0.10^{*}$ & $0.66 \pm 0.02$ \\
\hline Tryptophan & $63.9 \pm 2.7$ & $49.5 \pm 1.5$ & $65.4 \pm 3.2$ & $46.3 \pm 2.3$ & $103.3 \pm 8.6^{* *}$ & $57.4 \pm 1.3$ \\
\hline Kynurenine & $0.41 \pm 0.08$ & $0.25 \pm 0.06$ & $0.36 \pm 0.07$ & $0.23 \pm 0.04$ & $0.39 \pm 0.09$ & $0.21 \pm 0.04$ \\
\hline Tyrosine & $88.8 \pm 3.9$ & $71.1 \pm 3.9$ & $94.3 \pm 1.4$ & $66.2 \pm 1.5$ & $157.1 \pm 10.3^{* * *}$ & $91.8 \pm 3.8$ \\
\hline Guanosine & $229 \pm 16$ & $211 \pm 22$ & $207 \pm 40$ & $227 \pm 52$ & $208 \pm 32$ & $257 \pm 17$ \\
\hline Xanthine & $522 \pm 23^{*}$ & $363 \pm 168$ & $488 \pm 24^{*}$ & $316 \pm 27$ & $657 \pm 50^{* *}$ & $350 \pm 23$ \\
\hline Uric acid & $24.9 \pm 1.7^{* *}$ & $16.7 \pm 1.1$ & $41.6 \pm 0.7^{* *}$ & $14.9 \pm 1.4$ & $105.3 \pm 27.2^{* *}$ & $17.4 \pm 1.9$ \\
\hline
\end{tabular}

$n=10$ in each group; $*, p<0.01 ; * *, p<0.001$. 

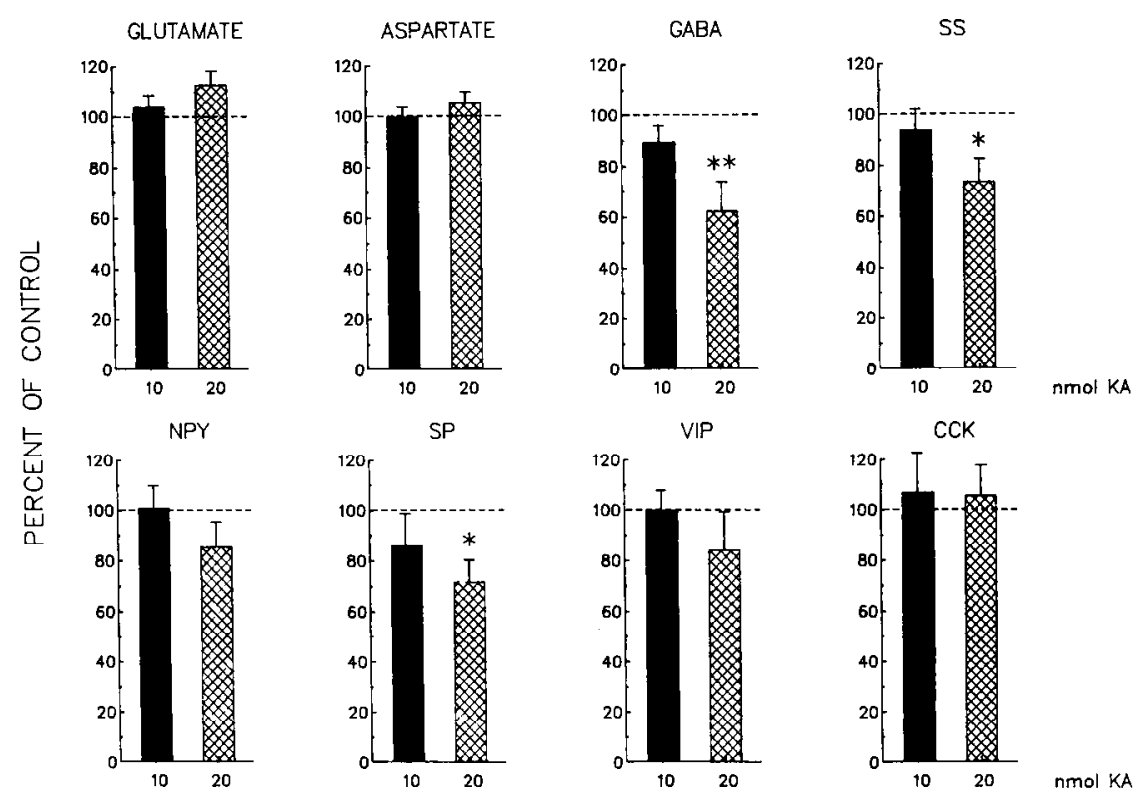

Figure 4. Effects of increasing doses of $K A$ on cortical neurochemical markers. There were dose-dependent significant reductions of GABA, SS, and SP concentrations. ${ }^{*}, p<0.05 ; * *, p<$ 0.01. Error bars represent SEM.

receptors can produce neuronal degeneration in vitro and in vivo. Studies in vitro show that much more prolonged exposure is required for non-NMDA agonists to produce neuronal death (Koh et al., 1990).

The role of NMDA and non-NMDA receptor agonists in neurologic diseases is under investigation. The most compelling evidence has linked NMDA receptors to neuronal degeneration in both ischemia and hypoglycemia (Choi, 1988). In experimental models of both these conditions, neuronal damage can be blocked with NMDA antagonists (Simon et al., 1984; Wieloch, 1985). There is also evidence that HD may be mediated by an NMDA-induced excitotoxic process. There is a preferential loss of NMDA receptors in the HD putamen (Young et al., 1989). In addition, NMDA excitotoxic striatal lesions show both pathologic and neurochemical similarities to $H D$, including relative sparing of cholincrgic and somatostatin-ncuropep- tide $\mathrm{Y}$ neurons (Beal et al., 1986a, 1989). It is also possible that non-NMDA receptors play a role in the pathogenesis of amyotrophic lateral sclerosis, or even AD (Spencer et al., 1987; Greenamyre et al., 1988; Weiss et al., 1989).

In partial ischemia, and also in HD and AD, there are selective patterns of neuronal death in the cerebral cortex. These patterns of neurotransmitter alterations in neurological diseases provide a background upon which one can test the validity of experimental models of neurological illness. The present study therefore examined whether excitotoxin lesions induced by agonists acting at the subtypes of acidic amino acid receptors can replicate the selective patterns of neuronal damage seen in several neurologic illnesses. Lesions with NMDA agonists (NMDA, quinolinic acid, and homocysteic acid) produced differential effects in the cerebral cortex as compared with lesions induced by the non-NMDA agonists AMPA and kainate. Increasing

Table 3. Neurochemical measurements in quinolinic acid-lesioned cerebral cortex (ng/mg protein)

\begin{tabular}{|c|c|c|c|c|c|c|}
\hline & \multicolumn{2}{|c|}{ Quinolinic acid, $120 \mathrm{nmol}$} & \multicolumn{2}{|c|}{ Quinolinic acid, $240 \mathrm{nmol}$} & \multicolumn{2}{|c|}{ Quinolinic acid, $480 \mathrm{nmol}$} \\
\hline & Left & Right & Left & Right & Left & Right \\
\hline Norepinephrine & $1.76 \pm 0.08$ & $2.07 \pm 0.06$ & $1.99 \pm 0.32$ & $1.95 \pm 0.26$ & $1.60 \pm 0.13$ & $1.62 \pm 0.18$ \\
\hline Dopamine & $2.23 \pm 0.28$ & $1.74 \pm 0.54$ & $2.64 \pm 0.99$ & $2.94 \pm 0.43$ & $1.73 \pm 0.28$ & $1.91 \pm 0.29$ \\
\hline 3,4-Dihydroxyphenylacetic acid & $1.80 \pm 0.29^{*}$ & $0.79 \pm 0.16$ & $2.21 \pm 0.39^{*}$ & $1.13 \pm 0.27$ & $2.48 \pm 0.14^{*}$ & $1.05 \pm 0.37$ \\
\hline Homovanillic acid & $1.62 \pm 0.23^{*}$ & $1.02 \pm 0.15$ & $1.51 \pm 0.19^{* *}$ & $0.89 \pm 0.12$ & $1.88 \pm 0.30^{* *}$ & $0.82+0.04$ \\
\hline Serotonin & $0.53 \pm 0.08$ & $0.61 \pm 0.06$ & $0.57 \pm 0.08$ & $0.55 \pm 0.04$ & $0.63 \pm 0.04$ & $0.56 \pm 0.24$ \\
\hline 5-Hydroxyindoleacetic acid & $0.87 \pm 0.08$ & $0.79 \pm 0.05$ & $0.68 \pm 0.13$ & $0.61 \pm 0.13$ & $0.77 \pm 0.08^{* *}$ & $0.57 \pm 0.06$ \\
\hline Tryptophan & $95.0 \pm 6.7$ & $75.1 \pm 3.3$ & $85.0 \pm 8.9$ & $68.8 \pm 5.7$ & $85.2 \pm 9.7$ & $61.5 \pm 9.3$ \\
\hline Kynurenine & $0.34 \pm 0.12$ & $0.29 \pm 0.10$ & $0.44 \pm 0.13$ & $0.43 \pm 0.22$ & $0.45 \pm 0.06$ & $0.43 \pm 0.21$ \\
\hline Tyrosine & $113.9 \pm 8.6^{*}$ & $92.0 \pm 6.3$ & $149.1 \pm 33.0^{*}$ & $82.0 \pm 2.4$ & $95.4 \pm 5.5$ & $60.2 \pm 3.4$ \\
\hline Guanosine & $343 \pm 38$ & $340 \pm 14$ & $363 \pm 71$ & $322 \pm 51$ & $207 \pm 29$ & $247 \pm 16$ \\
\hline Xanthine & $498 \pm 29^{*}$ & $356 \pm 16$ & $386 \pm 72$ & $271 \pm 31$ & $606 \pm 46^{* *}$ & $315 \pm 44$ \\
\hline Uric acid & $28.0 \pm 3.6^{* *}$ & $14.6 \pm 0.7$ & $34.5 \pm 7.4^{* *}$ & $20.9 \pm 7.7$ & $67.6 \pm 15.0^{* * *}$ & $19.7 \pm 3.8$ \\
\hline
\end{tabular}

$n-10$ in cach group; $*, p<0.01 ;{ }^{* *}, p<0.001 ; * * *, p<0.0001$. 
AMPA

GLUTAMATE

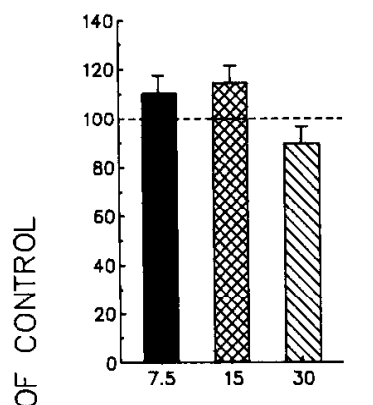

SS

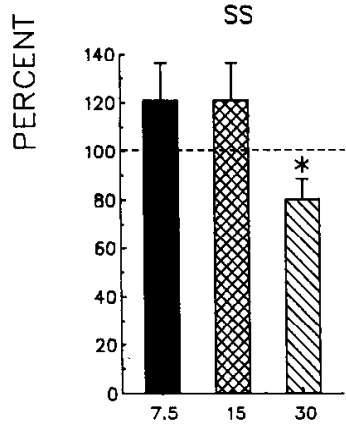

ASPARTATE
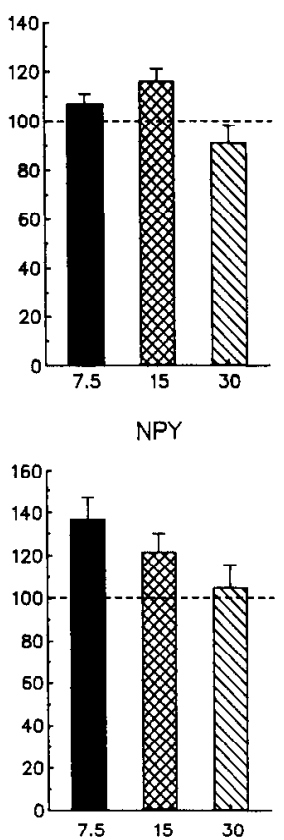

GABA

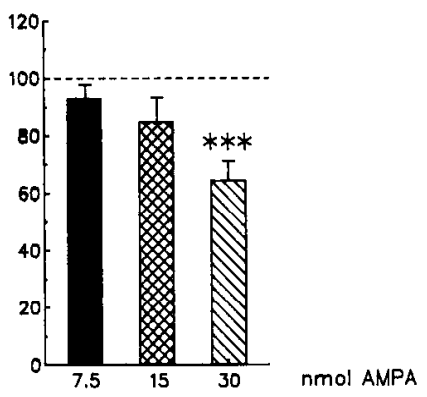

SP

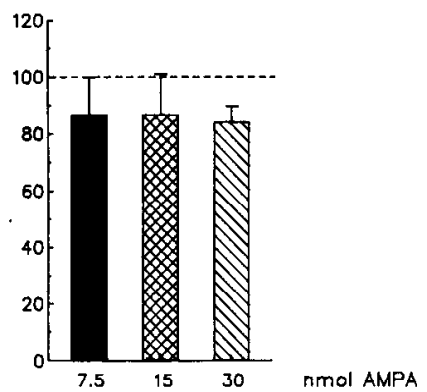

Figure 5. Effects of increasing doses of $A M P A$ on cortical neurochemical markers. There were dose-dependent significant reductions of GABA and SS concentrations. ${ }^{*}, p<0.05 ;{ }^{* * *}, p<$ 0.001 . Error bars represent SEM.

doses of NMDA agonists resulted in dose-dependent reductions of both glutamate and GABA, whereas there were no significant reductions in aspartate or a variety of neuropeptides. The extent of glutamate depletion is probably an underestimate of the extent of glutamatergic neuronal depletion, due to the presence of glutamate in both metabolic and neurotransmitter pools. Both NPY and SS showed significant increases, which were most marked at the lowest doses of the excitotoxins, and decreased with increasing doses, consistent with a relative but not absolute sparing of cortical neurons containing SS and NPY. SP and CCK showed significant increases at higher doses of NMDA agonists, while VIP was unchanged.

In contrast, lesions with non-NMDA agonists, which produced a comparable depletion of GABA to those with NMDA agonists, resulted in significant reductions of SS. SP was also depleted at the highest dose of KA. The histologic studies confirmed a relative sparing of NADPH-diaphorase, SS, VIP, and CCK neurons with NMDA agonists, in regions in which there was a marked depletion of pyramidal neurons (Figs. 6-8). In contrast with both KA and AMPA, there were significant depletions of NADPH-diaphorase and SS neurons. NMDA lesions depleted NADPH-diaphorase and SS neurons approximately $20 \%$, whereas the non-NMDA lesions resulted in an approximately $70 \%$ depletion. The sparing of NADPH-diaphorase and SS neurons was more striking in the cerebral cortex than that which occurs in the striatum. In the striatum, there is a marked depletion of the NADPH-diaphorase neurons in the center of the lesion, and sparing relative to enkephalin neurons can only

Table 4. Neurochemical measurements in homocysteic acid-lesioned cerebral cortex (ng/mg protein)

\begin{tabular}{|c|c|c|c|c|c|c|}
\hline & \multicolumn{2}{|c|}{ Homocysteate, $1250 \mathrm{nmol}$} & \multicolumn{2}{|c|}{ Homocysteate, $2500 \mathrm{nmol}$} & \multicolumn{2}{|c|}{ Homocysteate, $5000 \mathrm{nmol}$} \\
\hline & Left & Right & Left & Right & Left & Right \\
\hline Norepinephrine & $1.48 \pm 0.06$ & $1.68 \pm 0.10$ & $1.56 \pm 0.13$ & $1.77 \pm 0.17$ & $1.84 \pm 0.15$ & $2.11 \pm 0.19$ \\
\hline Dopamine & $2.34 \pm 1.18$ & $2.21 \pm 0.28$ & $1.83 \pm 0.80$ & $2.05 \pm 0.72$ & $2.07 \pm 0.77$ & $2.05 \pm 0.39$ \\
\hline 3,4-Dihydroxyphenylacetic acid & $0.74 \pm 0.25$ & $0.81 \pm 0.21$ & $1.59 \pm 0.37$ & $1.13 \pm 0.63$ & $1.40 \pm 0.43$ & $1.68 \pm 0.31$ \\
\hline Homovanillic acid & $0.72 \pm 0.12$ & $0.65 \pm 0.06$ & $1.01 \pm 0.12$ & $0.90 \pm 0.16$ & $1.95 \pm 0.55^{*}$ & $1.01 \pm 0.14$ \\
\hline Serotonin & $0.43 \pm 0.03$ & $0.43 \pm 0.04$ & $0.36 \pm 0.06$ & $0.34 \pm 0.05$ & $0.26 \pm 0.03$ & $0.31 \pm 0.08$ \\
\hline 5-Hydroxyindoleacetic acid & $0.73 \pm 0.10$ & $0.69 \pm 0.07$ & $0.83 \pm 0.08^{*}$ & $0.66 \pm 0.02$ & $1.36 \pm 0.10^{* *}$ & $0.85 \pm 0.05$ \\
\hline Tryptophan & $81.4 \pm 12.8$ & $59.2 \pm 4.7$ & $68.2 \pm 11.8^{*}$ & $35.5 \pm 5.0$ & $104.2 \pm 11.4^{*}$ & $52.7 \pm 4.4$ \\
\hline Kynurenine & $0.53 \pm 0.22$ & $0.29 \pm 0.03$ & $0.53 \pm 0.12$ & $0.30 \pm 0.11$ & $0.37 \pm 0.08$ & $0.27 \pm 0.06$ \\
\hline Tyrosine & $139.3 \pm 11.6^{*}$ & $86.8 \pm 9.2$ & $102.4 \pm 14.2^{m}$ & $58.9 \pm 5.9$ & $170.9 \pm 21.6^{* *}$ & $78.1 \pm 7.7$ \\
\hline Guanosine & $253 \pm 21$ & $200 \pm 26$ & $248 \pm 16$ & $220 \pm 16$ & $288 \pm 14$ & $265 \pm 16$ \\
\hline Xanthine & $421 \pm 59$ & $291 \pm 45$ & $422 \pm 54^{*}$ & $269 \pm 18$ & $522 \pm 31^{* *}$ & $296 \pm 18$ \\
\hline Uric acid & $37.2 \pm 4.4^{* *}$ & $15.2 \pm 1.2$ & $101.9 \pm 30.6^{* *}$ & $22.5 \pm 3.8$ & $232.5 \pm 63.4^{* *}$ & $27.3 \pm 3.9$ \\
\hline
\end{tabular}

$n=10$ in each group; ${ }^{*}, p<0.01 ; * *, p<0.001$. 
The Journal of Neuroscience, January 1991, 11(1) 153

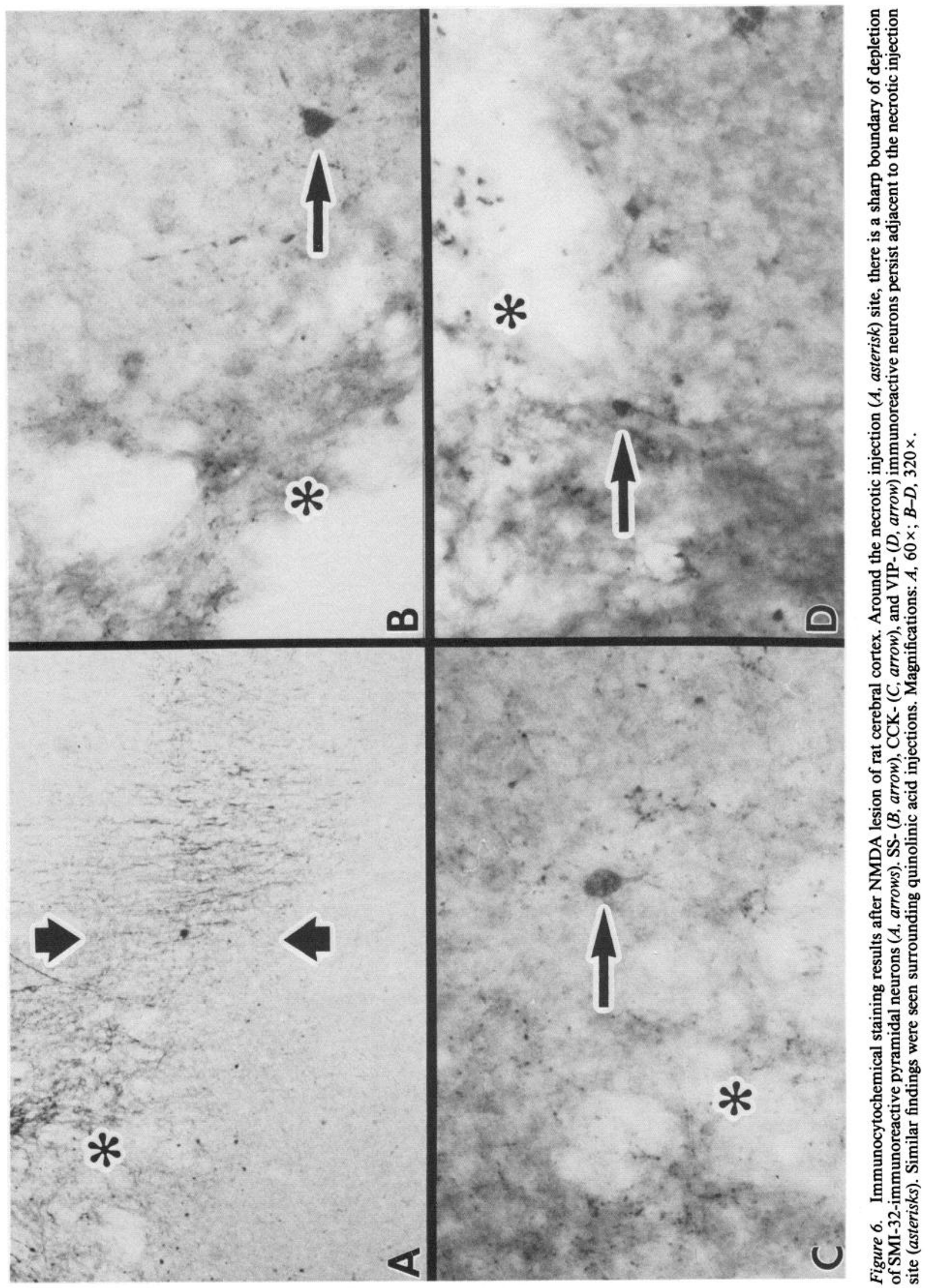


154 Beal et al. - Excitotoxin Lesions in the Cerebral Cortex

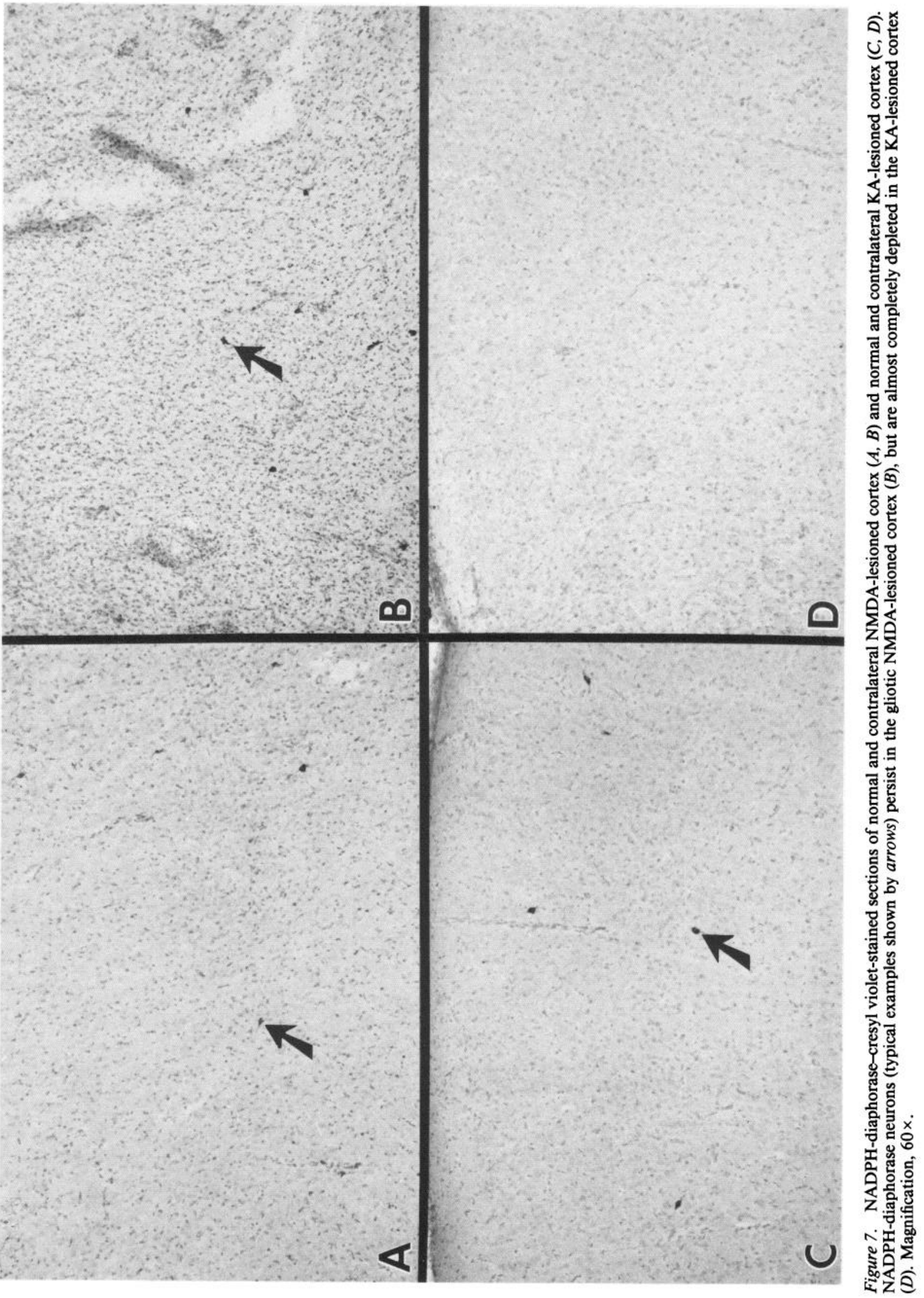




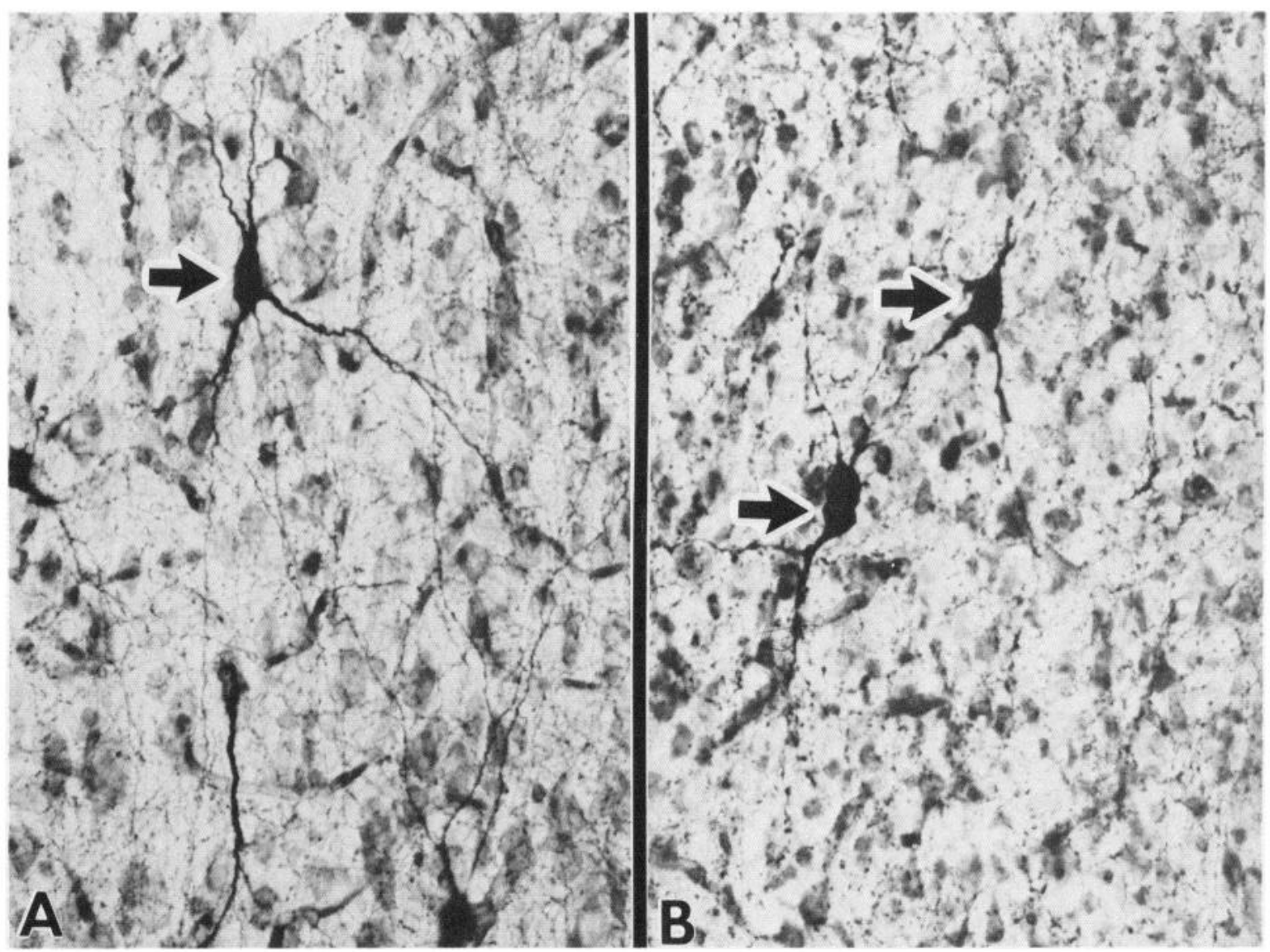

Figure 8. High-power view of NADPH-diaphorase-cresyl violet-stained cortex as seen normally $(A)$ in the contralateral NMDA-lesioned cortex $(B)$, showing neuronal loss and gliosis with sparing of NADPH-diaphorase neurons (arrows), which show some morphological changes. Magnification, $320 \times$.

be shown in the transition zone at the periphery of the lesion (Beal et al., 1989).

A relative sparing of NADPH-diaphorase neurons in cortical cell cultures was initially reported by Koh et al. (1986). These authors demonstrated that NADPH-diaphorase neurons were relatively spared in response to NMDA agonists, yet were preferentially depleted as compared with the total neuronal population in response to either quisqualate or kainate (Koh and Choi, 1988b). At extremely high doses of either NMDA or quinolinate, the NADPH-diaphorase neurons were depleted, consistent with a relative but not absolute resistance to these agents. Our present neurochemical findings are in accord with this. One previous immunocytochemical study of quinolinic acid lesions in the cerebral cortex also showed sparing of SS, NPY, and NADPH-diaphorase neurons, consistent with our present findings (Boegman and Parent, 1988). The finding that GABA concentrations are depleted following NMDA lesions appears at variance with the recent observation that GABAergic neurons are relatively spared by NMDA excitotoxin lesions in cortical cultures (Tecoma and Choi, 1989). GABAergic neurons in the cerebral cortex, however, comprise several subpopulations. GABAergic neurons can be divided into 2 classes, containing either parvalbumin or calbindin (Hendry et al., 1989). CCK, SP, SS, and NPY neurons all show colocalization with GABA in the cerebral cortex (Jones, 1986). The present findings suggest that this population of GABAergic neurons is resistant to NMDA, while other populations may not show comparable resistance. It is of interest that VIP, which does not colocalize with GABA (Jones, 1986), was the one neuropeptide that did not show significant increases following NMDA lesions.

The most plausible explanation for relative sparing of neuropeptide-containing interneurons following NMDA cortical lesions is that these neurons receive fewer excitatory amino acid afferents, and exhibit fewer NMDA receptors, than other neurons. Consistent with this notion, a recent ultrastructural study of NPY neurons in both the cerebral cortex and the striatum showed that synaptic inputs to proximal dendrites and somata were rare, as compared with neighboring neurons (Aoki and Pickel, 1989). This suggests that fewer and weaker inputs may modulate the excitability of NPY-containing neurons. GABAergic neurons receive both excitatory and inhibitory afferents, but the relative proportions are unclear (DeFelipe and Jones, 1985). Most dendritic spines that are postsynaptic to glutamatergic terminals probably arise from pyramidal neurons (Conti et al., 1989), which may account for the vulnerability of these neurons.

The present studies confirm previous findings that cortical afferents are spared by excitotoxin lesions (Isacson et al., 1988). There was no significant depletion of norepinephrine, dopamine, or serotonin. This is consistent with other studies showing no alteration in ChAT activity in the cerebral cortex following excitotoxin lesions (Isacson et al., 1988). There were significant 
dose-dependent increases in both dopamine and serotonin metabolites, consistent with increased turnover. Similar findings occur with striatal lesions at 1 week (Aldinio et al., 1985; Mazzari et al., 1986). There were also increased concentrations of both tryptophan and tyrosine, which may reflect neovascularization after the lesions, with increased transport into the brain (Iadecola et al., 1989; Shigematsu et al., 1989). The most striking finding was marked (5-10-fold) dose-dependent significant increases in uric acid concentrations with all excitotoxin lesions examined. There were also increases in xanthine concentrations, but these were much less marked. Increased uric acid concentrations, therefore, are an extremely sensitive marker of excitotoxin lesions. We have recently observed similar increases in uric acid following striatal lesions at $7 \mathrm{~d}$, but levels are normal at 3 and 6 months (M. F. Beal et al., unpublished observations).

The finding of increased uric acid concentrations is of uncertain significance. Several stimuli, including drug administration, feeding and drinking behavior, and motivated lever pressing, result in increased extracellular levels of uric acid (Kendrick et al., 1986; Mueller, 1987; Joseph et al., 1989; O'Neill, 1990). Excitatory amino acids can also release ${ }^{3} \mathrm{H}$-adenosine from the cerebral cortex in vivo (Perkins and Stone, 1983). Increased uric acid could therefore represent a degradation product of adenosine (O'Neill, 1986). Alternatively, because uric acid is derived from purines, which are involved in cellular energy metabolism, it may be an index of regional metabolic activity. This latter possibility is supported by observations in the ischemic brain showing marked increases in xanthine and uric acid for up to $48 \mathrm{hr}$ following middle cerebral artery occlusion (Kanemitsu et al., 1988). Striatal glucose metabolism remains elevated $5 \mathrm{~d}$ after an ibotenic acid lesion (Owman et al., 1983), though after several weeks, there are significant reductions in glucose metabolism (Isacson et al., 1984).

The present findings show several similarities in the pattern of neuronal degeneration that occurs following ischemia and in the HD cerebral cortex, as compared with that seen following NMDA excitotoxin lesions in the cerebral cortex. With ischemia in the neonatal cerebral cortex, both concentrations of SS and NPY and numbers of NADPH-diaphorase neurons are spared (Ferriero et al., 1988). We found similar sparing of NADPHdiaphorase neurons, as well as preservation of SS, NPY, and SP concentrations, following cortical ischemic damage in adult gerbils (Uemura et al., 1990). VIP neurons in the frontoparietal cortex and the hippocampus are also spared by transient forebrain ischemia (Grimaldi et al., 1989). Some GABAergic neurons in the cerebral cortex are vulnerable to ischemia (Sloper et al., 1980; Romijn, 1989), though other populations in the hippocampus are resistant (Johansen et al., 1989; Nitsch et al., 1989). Pyramidal neurons appear to be particularly vulnerable to ischemia (Iizuka et al., 1989).

In HD, there has been uncertainty concerning the extent of pathologic involvement in the cerebral cortex. A recent morphometric study showed a marked reduction in the volume of the cerebral cortex (de la Monte et al., 1988). Our recent neurochemical studies showed marked increases in CCK, NPY, and VIP concentrations, with smaller increases in SS and SP (Beal et al., 1988a, 1989b; Mazurek et al., 1989a,b). Glutamate concentrations were either unchanged or showed small decreases (Ellison et al., 1987), consistent with another report (Reynolds and Pearson, 1987). These findings are consistent with a loss of pyramidal neurons containing glutamate and relative sparing or up-regulation of neuropeptide-containing interneurons. In sup- port of this, our recent immunohistochemical studies showed preservation of NPY neurons despite a loss of neurofilamentstained pyramidal neurons in the HD cerebral cortex (Cudkowicz and Kowall, 1990).

The present findings provide further evidence favoring an NMDA excitotoxin mechanism both in ischemic cortical damage and in HD. NMDA excitotoxic lesions in the cerebral cortex are similar to findings in ischemia in that there is a depletion of both GABAergic and pyramidal neurons, yet a relative preservation of NADPH-diaphorase and VIP neurons. In the HD cerebral cortex, there is a depletion of pyramidal neurons, yet a preservation of neuropeptide $Y$ neurons, as seen with NMDA excitotoxin lesions. In addition, there are increases in concentrations of neuropeptides consistent with findings following NMDA excitotoxin lesions. It is of interest that the largest and most consistent increases were in NPY and CCK, similar to findings in HD. GABA concentrations are not significantly depleted in $\mathrm{HD}$, in contrast to what we observed with excitotoxin lesions. Other studies, however, have shown that, following chronic excitotoxin lesions, the cerebral cortex shrinks, and glutamic acid decarboxylase activity, a marker of GABAergic neurons, returns to normal (Isacson et al., 1988). Atrophy of the cerebral cortex in HD may therefore account for the normal GABA concentrations, despite a loss of GABAergic neurons.

In $\mathrm{AD}$, there are reductions in SS concentrations, as well as morphologic changes in SS neurons (Beal et al., 1986c; Kowall and Beal, 1988). Other neuropeptides, however, are much less affected (Beal et al., 1987). This pattern of neurotransmitter involvement was most closely replicated by non-NMDA receptor agonists in the present study. Cortical lesions with nonNMDA agonists also result in shrinkage of the large basal forebrain cholinergic neurons, as well as reductions in cortical ChAT activity, similar to findings in AD (Isacson et al., 1988).

The present findings show that excitotoxin lesions with NMDA and non-NMDA agonists result in selective patterns of neuronal degeneration. They provide further circumstantial evidence that excitatory amino acid receptors may be involved in the pathogenesis of both acute and chronic neurologic illnesses.

\section{References}

Abe H, Engler D, Molitch ME, Bollinger-Gruber J, Reichlin S (1985) Vasoactive intestinal polypeptide is a physiological mediator of prolactin release in the rat. Endocrinology 116:1383-1390.

Aldinio C, Mazzari S, Toffano G, Kohler C, Schwarcz R (1985) Effects of intracerebral injections of quinolinic acid on serotonergic neurons in the rat brain. Brain Res 341:57-65.

Aoki C, Pickel VM (1989) Neuropeptide Y in the cerebral cortex and the caudate-putamen nuclei: ultrastructural basis for interactions with GABAergic and non-GABAergic neurons. J Neurosci 9:4333-4354.

Arnold MA, Reppert SM, Rorstad O, Sagar SM, Keutmann HT, Perlow MJ, Martin JB (1982) Temporal patterns of somatostatin immunoreactivity in the cerebrospinal fluid of rhesus monkeys. Effect of environmental lighting. J Neurosci 2:674-680.

Beal MF, Mazurek MF (1987) Substance P-like immunoreactivity is reduced in Alzheimer's disease cerebral cortex. Neurology 37:12051209.

Beal MF, Kowall NW, Ellison DW, Mazurek MF, Swartz KJ, Martin JB (1986a) Replication of the neurochemical characteristics of Huntington's disease by quinolinic acid. Nature 321:168-171.

Beal MF, Mazurek MF, Lorenz L.I, Chattha GK, Ellison DW, Martin JB (1986b) An examination of neuropeptide Y postmortem stability in an animal model simulating human autopsy conditions. Neurosci Lett 64:69-74.

Beal MF, Mazurek MF, Svendsen CN, Bird ED, Martin JB (1986c) Widespread reduction of somatostatin-like immunoreactivity in the cerebral cortex in Alzheimer's disease. Ann Neurol 20:489-495. 
Beal MF, Kowall NW, Mazurek MF (1987) Neuropeptides in Alzheimer's disease. J Neural Transm [Suppl] 24:163-174.

Beal MF, Ellison DW, Mazurek MF, Swartz KJ, Malloy JR, Bird ED, Martin JB (1988a) A detailed examination of substance $P$ in pathologically graded cases of Huntington's disease. J Neurol Sci 84:5161.

Beal MF, Mazurek MF, Ellison DW, Swartz KJ, MacGarvey U, Bird ED, Martin JB (1988b) Somatostatin and neuropeptide Y concentrations in pathologically graded cases of Huntington's disease. Ann Neurol 23:562-569.

Beal MF, Kowall NW, Swartz KJ, Ferrante RJ, Martin JB (1989) Differential sparing of somatostatin-neuropeptide $Y$ and cholinergic neurons following striatal excitotoxin lesions. Synapse 3:38-47.

Boegman RJ, Parent A (1988) Differential sensitivity of neuropeptide Y, somatostatin and NADPH-diaphorase neurons in rat cortex and striatum to quinolinic acid. Brain Res 445:358-362.

Bohlen P, Stein S, Dairman W, Udenfriend S (1973) Fluorometric assay of proteins in the nanogram range. Arch Biochem Biophys 155: 213-220.

Choi DW (1988) Glutamate neurotoxicity and diseases of the nervous system. Neuron 1:623-634.

Conti F, DeFelipe J, Farinas I, Manzoni T (1989) Glutamate-positive neurons and axon terminals in cat sensory cortex: a correlative light and electron microscopic study. J Comp Neurol 290:141-153.

Coyle JT, Schwarcz R (1976) Lesion of striatal neurons with kainic acid provides a model for Huntington's chorea. Nature 263:244-246.

Cudkowicz M, Kowall NW (1990) Degeneration of pyramidal projection neurons in Huntington's disease cortex. Ann Neurol 27:200204.

DeFelipe J, Jones EG (1985) Vertical organization of gamma-aminobutyric acid-accumulating intrinsic neuronal systems in monkey cerebral cortex. J Neurosci 5:3246-3260.

de la Monte SM, Vonsattel JP, Richardson EP (1988) Morphometric demonstration of atrophic change in the cerebral cortex. J Neuropathol Exp Neurol 47:516-525.

Ellison DW, Beal MF, Martin JB (1987a) Amino acid neurotransmitters in postmortem human brain analyzed by high performance liquid chromatography with electrochemical detection. J Neurosci Mcth 19:305-315.

Ellison DW, Beal MF, Mazurek MF, Malloy JR, Bird ED, Martin JB (1987b) Amino acid neurotransmitter abnormalities in Huntington's disease and the quinolinic acid animal model of Huntington's disease. Brain 110:1657-1674.

Fagg GE, Foster AC, Ganong AH (1986) Excitatory amino acid synaptic mechanisms and neurological function. Trends Pharmacol Sci 7:357-363.

Ferriero DM, Arcavi LJ, Sagar SM, McIntosh TK, Simon RD (1988) Selective sparing of NADPH-diaphorase neurons in neonatal hypoxia-ischemia. Ann Neurol 24:670-676.

Greenamyre JT, Maragos WF, Albin RL, Penney JB, Young AB (1988) Glutamate transmission and toxicity in Alzheimer's disease. Prog Neuropsychopharmacol Biol Psychiatr 12:421-430.

Grimaldi R, Zini I, Ferraguti $F$, Cortelli P, Fuxe K, Agnati LF, Zoli M (1989) Effects of transient forebrain ischaemia on vasoactive intestinal polypeptide-immunoreactive neuronal populations in the frontoparietal cortex and hippocampal formation of the male rat. Acta Physiol Scand 136:289-290.

Hendry SHC, Jones EG, Emson PC, Lawson DEM, Heizmann CW, Streit P (1989) Two classes of cortical GABA neurons defined by differential calcium binding protein immunoreactivities. Exp Brain Res 76:467-472.

ladecola C, Anneric SP, Reis DJ (1989) Local and remote microvascular changes in excitotoxin-induced focal brain lesions. Brain Res 501:188-193.

Iizuka H, Sakatani K, Young W (1989) Selective cortical neuronal damage after middle cerebral artery occlusion in rats. Stroke 20:15161523.

Isacson O, Brundin P, Kelly PAT, Gage FH, Bjorklund A (1984) Functional neuronal replacement by grafted striatal neurons in the ibotenic acid-lesioned rat striatum. Nature 311:458-460.

Isacson O, Wictorin K, Fischer W, Sofroniew MV, Bjorklund A (1988) Fetal cortical suspension grafts to the excitotoxically lesioned neocortex: anatomical and neurochemical studies of trophic interactions. Prog Brain Res 78:13-26.

Johansen F-F, Lin C-T, Schoushoe A, Wu J-Y (1989) Immunocyto- chemical investigation of L-glutamic acid decarboxylase in the rat hippocampal formation: the influence of transient cerebral ischemia. J Comp Neurol 281:40-53.

Jones EG (1986) Neurotransmitters in the cerebral cortex. J Neurosurg 65:135-153.

Joseph MH, Hodges H, Gray JA (1989) Lever pressing for food reward and in vivo voltammetry: evidence for increases in extracellular homovanillic acid, the dopamine metabolite, and uric acid in the rat caudate nucleus. Neuroscience 32:195-201.

Kanemitsu H, Tamura A, Kirino T, Karasawa S, Sano K, Iwamoto T, Yoshiura M, Iriyama KC (1988) Xanthine and uric acid levels in rat brain following focal ischemia. J Neurochem 51:1882-1885.

Kendrick KM, Baldwin BA, Cooper TR, Sharman DF (1986) Uric acid is released in the zona incerta of the subthalamic region of the sheep during rumination and in response to feeding and drinking stimuli. Neurosci Lett 70:272-277.

Koh J-Y, Choi DW (1988a) Cultured striatal neurons containing NADPH-diaphorase or acetylcholinesterase are selectively resistant to injury by NMDA receptor agonists. Brain Res 446:374-378.

Koh J-Y, Choi DW (1988b) Vulnerability of cultured cortical neurons to damage: differential susceptibility of neurons containing NADPHdiaphorase. J Neurosci 8:2153-2163

Koh J-Y, Peters S, Choi DW (1986) Neurons containing NADPHdiaphorase are selectively resistant to quinolinate toxicity. Science 234:73-76.

Koh J-Y, Goldberg MP, Hartley DM, Choi DW (1990) Non-NMDA receptor-mediated neurotoxicity in cortical cultures. J Neurosci 10: 693-705.

Kowall NW, Beal MF (1988) Cortical somatostatin, neuropeptide Y, and NADPH-diaphorase neurons: normal anatomy and alterations in Alzheimer's disease. Ann Neurol 23:105-114.

Matson WR, Gamache PG, Beal MF, Bird ED (1987) EC array sensor concepts and data. Life Sci 41:905-908.

Mazurek MF, Beal MF, Ellison DW, Knowlton SF, Swartz KJ, Martin JB (1989a) Cholecystokinin immunoreactivity in Huntington's disease: widespread increases in postmortem cerebral cortex. In: The neuropeptide cholecystokinin (CCK) anatomy and biochemistry, receptors, pharmacology and physiology (Hughes J, Dockray G, Woodruff G, cds), pp 28-32. New York: Wiley.

Mazurek MF, Beal MF, Knowlton SF, Swartz KJ, Martin JB (1989b) Elevated concentrations of cholecystokinin and vasoactive intestinal polypeptide in Huntington's disease cerebral cortex. Neurology [Suppl 1] 39:203.

Mazzari S, Aldino C, Beccaro M, Toffano G, Schwarcz R (1986) Intracerebral quinolinic acid injection in the rat: effects on dopaminergic neurons. Brain Res 380:309-316.

McGeer EG, McGeer PL (1976) Duplication of biochemical changes of Huntington's chorea by intrastriatal injections of glutamic and kainic acids. Nature 263:517-519.

Mueller K (1987) Voltammetric evidence in vivo of cholinergic modulation of extracellular ascorbic acid and uric acid in rat striatum. Brain Res 408:313-316.

Nitsch C, Scotti A, Sommacal A, Kalt G (1989) GABAergic hippocampal neurons resistant to ischemia-induced neuronal death contain the $\mathrm{Ca}^{2+}$-binding protein parvalbumin. Neurosci Lett 105:263-268.

O'Neill R (1986) Adenosine modulation of striatal neurotransmitter release monitored in vivo using voltametry. Neurosci Lett 63:11-16.

O'Neill RD (1990) Uric acid levels and dopamine transmission in rat striatum: diurnal changes and effects of drugs. Brain Res 507:267272.

Owman C, Andersson J, Diemer NH, Fuxe K (1983) Effect of ibotenic acid stereotactically injected into striatum or hippocampus on local blood flow and glucose utilization in rats. In: Excitotoxins (Fuxe K, Roberts P, Schwarcz R, eds), pp 251-255. New York: Plenum.

Perkins MN, Stone TW (1983) In vivo release of ${ }^{3} \mathrm{H}$-purines by quinolinic acid and related compounds. Br J Pharmacol 80:263-267.

Reynolds GP, Pearson SJ (1987) Decreased glutamic acid and increased 5-hydroxytryptamine in Huntington's disease brain. Neurosci Lett 78:233-238.

Romijn HJ (1989) Preferential loss of GABAergic neurons in hypoxiaexposed neocortical slab cultures is attenuated by the NMDA receptor blocker D-2-amino-7-phosphonoheptanoate. Brain Res 501:100-104. Schwarcz R, Foster AC, French ED, Whetsell WO, Kohler C (1984) Excitotoxin models for neurodegenerative disorders. Life Sci 35:1932. 
Shigematsu K, Kamo H, Akiguchi I, Kimura J, Kameyama M, Kimura H (1989) Neurovascularization in kainic acid-induced lesions of rat striatum. An immunohistochemical study with laminin. Brain Res 501:215-222.

Simon RP, Swan JH, Griffin T, Meldrum BS (1984) Blockade of $N$-methyl-D-aspartate receptors may protect against ischaemic damage in the brain. Science 226:850-852.

Sloper JJ, Johnson P, Powell TPS (1980) Selective degeneration of interneurons in the motor cortex of infant monkeys following controlled hypoxia: a possible cause of epilepsy. Brain Res 198:204-209.

Spencer PS, Nunn PB, Hugon J, Ludolph AC, Ross SM, Roy N, Robertson RC (1987) Guam amyotrophic lateral sclerosis-parkinsonism-dementia linked to a plant excitant neurotoxin. Science 237:517522.

Tecoma ES, Choi DW (1989) GABAergic neocortical neurons are resistant to NMDA receptor-mediated injury. Neurology 39:676-682.
Uemura Y, Kowall NW, Beal MF (1990) Selective sparing of NADPHdiaphorase-somatostatin-neuropeptide $\mathrm{Y}$ neurons in ischemic gerbil striatum. Ann Neurol 27:620-625.

Wahlestedt C, Blendy JA, Kellar JJ, Heilig M, Widerlov E, Ekman R (1990) Electroconvulsive shocks increase the concentration of neocortical and hippocampal neuropeptide Y (NPY)-like immunoreactivity in the rat. Brain Res 507:65-68.

Weiss JH, Koh J, Choi DW (1989) Neurotoxicity of beta- $N$-methylamino-L-alanine (BMAA) and beta- $N$-oxalylamino-L-alanine (BOAA) on cultured cortical neurons. Brain Res 497:64-72.

Wieloch T (1985) Hypoglycemia-induced neuronal damage prevented by an $N$-methyl-D-aspartate antagonist. Science 230:681-683.

Young AB, Greenamyre JT, Hollingsworth Z, Albin R, D'Amato C, Shoulson I, Penney JB (1989) NMDA receptor losses in putamen from patients with Huntington's disease. Science 241:981-983. 